\title{
ANÁLISE ECONÔMICO-FINANCEIRA: UM ESTUDO DE CASO DA PETROBRÁS
}

\author{
Samir Alves de Moraes, José Gabriel Cicero Pereira, Sonia Sanae Sato, José Carlos do Nascimento
}

Universidade do Oeste Paulista - UNOESTE, Presidente Prudente, SP. E-mail: ssamyr@hotmail.com; gabrielpereira06@hotmail.com; sonia@unoeste.br; nascimento@unoeste.br

\section{RESUMO}

Uma das formas de se obter informações sobre a situação econômico-financeira de uma entidade, é por meio da interpretação dos dados encontrados em seus demonstrativos contábeis. Nesse contexto, essa pesquisa teve como objetivo realizar um diagnóstico da situação econômicofinanceira da empresa Petróleo Brasileiro S.A (Petrobrás) por meio das análises vertical, horizontal e de índices econômico-financeiros no período de 2014 a 2016. Esta pesquisa se caracterizou como qualiquantitativa, descritiva e estudo de caso, e utilizou como fonte de coleta de dados as pesquisas bibliográfica e documental. Os resultados das análises demonstraram que $82 \%$ em média dos ativos da Petrobrás são de longo prazo, e destes $71 \%$ em média estão classificados no Imobilizado, sendo que a empresa financiou parte desses ativos com recursos de terceiros de longo prazo, em média 55\%. Basicamente, o montante de despesas da empresa foi maior do que suas receitas, o que a levou a obter prejuízo líquido no período analisado. Em linhas gerais, a empresa apresentou uma boa situação de liquidez e de atividade, entretanto, apresentou alto nível de endividamento e não apresentou rentabilidade para seus acionistas.

Palavras-chaves: Análise Econômico-Financeira. Análise Vertical. Análise Horizontal. Análise de Índices. Petrobrás.

\section{FINANCIAL-ECONOMIC ANALYSIS: A STUDY OF THE PETROBRÁS CASE}

\section{ABSTRACT}

One of the ways to obtain information of the financial-economic situation of a entity, is through the interpretation $s$ datas fouded in it's financial statements. In this context, this research has the objective of making a diagnosis of the financial-economic situation of Petróleo Brasileiro S.A. company (Petrobrás) by means of vertical, horizontal analisys and financial-economic indexes in the period from 2014 to 2016. This research was characterized as qualitative-quantitative, descritive and case study, and sed as data collect source documentary and bibliographic researchs. The results of the analisys demonstrated that in avarege $82 \%$ of the actives of Petrobrás ar in long term, and of these in avarege $71 \%$ are classified as immobilized, being tha the company financied arte of these actives with thirds resources in long term, in avarege 55\%. Basically, the amout of expenses of the company was higher than the revenues. Wich led it to obtain loss in the anlized period. In a nutshell, the company, presented good liquidity and activity situation, however, it presented a high level of indebtedness and didn't present profitability for its shareholders.

Keywords: Financial-Economic Analysis. Vertical Analysis. Horizontal Analysis. Indexes Analysis. Petrobrás.

\section{INTRODUÇÃO}

As pessoas jurídicas são importantes entidades presentes na sociedade, uma vez que estas são responsáveis pela produção de bens e serviços que vem contribuindo significativamente para o desenvolvimento de uma sociedade moderna. Deste modo, é importante que as organizações 
tenham conhecimento do seu desempenho econômico-financeiro, tanto para que possam avaliar sua performance operacional, quanto para identificar em que situação está a sua saúde econômica e financeira, e a partir disto, poderem tomar decisões financeiras acertadas relacionadas a investimentos, financiamentos, formação de patrimônio, vendas, etc. Uma das formas de se obter informações sobre a situação econômico-financeira de uma empresa, é por meio da interpretação dos dados encontrados em seus demonstrativos contábeis. A esse respeito, Blatt (2001) comenta que é por meio da análise dos demonstrativos contábeis que é possível determinar de maneira exata a involução ou a evolução das situações econômica e financeira de uma entidade.

Assim, a análise das demonstrações contábeis tem por objetivo revelar a situação financeira passada e atual, e a partir disto, projetar uma posição futura da empresa. Em linhas gerais, esta análise é uma metodologia de estudo que tem por objetivo compreender a situação econômica e financeira de uma determinada empresa.

Nesse contexto, essa pesquisa teve como objetivo realizar um diagnóstico da situação econômico-financeira da empresa Petróleo Brasileiro S.A (Petrobrás) por meio das análises vertical, horizontal e de índices econômico-financeiros no período de 2014 a 2016. A escolha pela empresa Petrobrás foi motivada pelo escândalo midiático gerado pela operação Lava Jato que a fez perder credibilidade. Deste modo, por se tratar de uma empresa estatal de economia mista em que o Governo do Brasil é o acionista majoritário, qualquer variação que ocorra em suas operações pode afetar positiva ou negativamente a população brasileira. Logo, por se tratar de uma das mais importantes empresas estatais do Brasil, a análise dos demonstrativos contábeis dessa petrolífera, será de grande valia para a população brasileira, bem como, para os investidores interessados, pois trará importantes informações sobre a real situação econômico-financeira dessa sociedade empresária.

\section{METODOLOGIA}

Para a realização dessa pesquisa foi utilizada a abordagem qualitativa, que na ótica de Guerra (2014) é uma pesquisa que objetiva aprofundar-se na compreensão dos fenômenos, e interpretá-los de acordo com a perspectiva dos próprios autores do estudo. Sendo assim, essa pesquisa buscou analisar e interpretar os demonstrativos contábeis da Petrobrás no período abrangido entre 2014-2016. É importante salientar que essa pesquisa também teve uma abordagem quantitativa, que é aquela que "recorre à linguagem matemática para descrever as causas de um fenômeno, as relações entre as variáveis, etc." (FONSECA, 2002, apud SILVEIRA; CÓRDOVA, 2009, p. 33). No caso dessa pesquisa, recorreu-se aos métodos quantitativos quando do uso da matemática para os cálculos das análises horizontal, vertical e de índices econômicofinanceiros. O estudo tratou-se de uma pesquisa descritiva, que segundo Cervo, Bervian e Silva (2007, p.61) é aquele que "observa, registra, analisa e correlaciona fatos ou fenômenos (variáveis)". Assim, após os cálculos mencionados acima, os pesquisadores do presente estudo os descreveram e os analisaram sob a ótica econômica e financeira.

A coleta de dados dessa pesquisa foi realizada por meio de fontes bibliográficas, que de acordo com Gil (2010), esse tipo de pesquisa é elaborado com base em material já publicado, tais como livros, revistas, jornais e dissertações. Assim, foram analisados os livros e artigos que abordam conceitos a respeito da temática discutida e que apresentam diferentes técnicas de análises econômico-financeira. Devido à necessidade de análise aos demonstrativos contábeis da Petrobrás, essa pesquisa mostrou-se ainda como sendo de fontes documentais, que de acordo com Fonseca (2002, apud SILVEIRA; CÓRDOVA, 2009, p. 37) "recorre a fontes mais diversificadas e dispersas, sem tratamento analítico, tais como: tabelas estatísticas, jornais, revistas, relatórios, documentos oficiais [...]". Levando em consideração o pensamento de Gil (2010), pode-se afirmar 
que essa pesquisa se caracterizou como um estudo de caso, pois envolveu o estudo detalhado a respeito da situação econômico-financeira de uma única empresa, a Petrobrás.

\section{RESULTADOS E DISCUSSÕES}

A análise econômico-financeira dos demonstrativos contábeis é feita por meio de um conjunto de técnicas, sendo as mais difundidas, a Análise Vertical, a Análise Horizontal, e a Análise de Índices Econômico-financeiros, sendo que esta última por ser realizada pela análise de quatro grandes aspectos empresariais: liquidez, atividade, endividamento e lucratividade. Quanto aos demonstrativos contábeis, destacam-se o Balanço Patrimonial e a Demonstração do Resultado do Exercício, uma vez que estes refletem a situação operacional e patrimonial de uma empresa, bem como o seu desempenho econômico e financeiro. O Balanço Patrimonial (BP) segundo Assaf Neto (2012) é um demonstrativo contábil indispensável para iniciar uma análise econômico-financeira, pois por meio dele é possível obter informações das fontes de recursos de uma empresa, sejam próprias ou de terceiros, e a forma que esta os administram para gerar benefícios econômicos que satisfaçam os financiadores do negócio. Em outras palavras, a análise do BP permite identificar os bens e direitos (Ativos) de uma organização, bem como suas obrigações (Passivos). De acordo com Dantas (2015), a Demonstração do Resultado do Exercício (DRE), traz de forma resumida e vertical as origens (receitas) e as aplicações de recursos (custos, despesas, impostos, contribuições e participações), que tornam possível determinar o resultado de uma empresa ao final do seu exercício social, que pode ser lucro ou prejuízo.

\section{ANÁLISES VERTICAL E HORIZONTAL}

Considerando o exposto, por meio da análise vertical do BP da Petrobrás, foi possível verificar a participação de cada uma das suas contas em relação ao total do ativo/passivo apurado em cada ano. Assim, a análise vertical das contas do Ativo da companhia demonstrou que a empresa no período analisado tem mais capital investido em seu Ativo Não Circulante (ANC) do que em seu Ativo Circulante (AC) que, em média, representaram 82,0\% e 18,0\% respectivamente do Ativo Total (AT) da empresa, e esse nível de investimentos no ANC praticamente se manteve no mesmo patamar nos três anos analisados. Também foi possível observar que o capital investido nas contas do ANC basicamente se concentrou nos ativos imobilizados, uma vez que nos anos estudados, essa conta representou em média $73,2 \%$ do AT.

Em relação a análise horizontal das contas do ativo do BP, foi possível verificar quer o AT da companhia apresentou um crescimento de 13,5\% de 2014 a 2015, que foi decorrente do AC que cresceu muito mais que o ANC, sendo estes aumentos de $24,9 \%$ e $11,1 \%$ respectivamente. Porém, em 2016 o AT da empresa diminuiu 10,6\% e, esse fato foi por conta da redução de $13,5 \%$ do seu AC e 9,9\% do seu ANC. Assim, foi possível perceber quer o AT da companhia apresentou um crescimento inexpressivo de 1,5\% de 2014 a 2016. A conta Caixa e Equivalentes de Caixa apresentou um aumento significativo de $121,2 \%$ de 2014 para 2015. Porém no mesmo intervalo, as Aplicações Financeiras caíram 87,7\%. Em contrapartida, entre 2014 e 2015 ocorreram dois aumentos importantes, do Realizável a Longo Prazo que cresceu $51,4 \%$, e do Imobilizado que aumentou 8,4\%. Já em 2016 a companhia reduziu 29,4\% da sua conta Caixa e Equivalente de Caixa, 12,4\% em seu Realizável a Longo Prazo e 9,2\% do seu Imobilizado.

$\mathrm{Na}$ análise vertical das contas do passivo da empresa foi possível identificar que em 2014, $50,4 \%$ das obrigações totais da Petrobrás eram de longo prazo, ou seja, estavam classificadas no Passivo Não Circulante (PNC), enquanto que 10,4\% eram de curto prazo e estavam classificadas no Passivo Circulante (PC), e o restante $39,2 \%$ constituía o Patrimônio Líquido (PL) da empresa. Nesse ano, o PNC sozinho representou pouco mais da metade das obrigações totais da empresa. Em 2015, ocorreu um aumento na participação do PC e uma diminuição do Patrimônio Líquido para $12 \%$ e $29 \%$ respectivamente. Deste modo, os Empréstimos e Financiamentos do PNC passaram a 
representar 59\% do Passivo Total. Em 2016, a Petrobrás praticamente manteve a mesma situação de compromissos à longo prazo, apresentando um PNC de 58,5\%, já seu PC apresentou redução e foi para $10,1 \%$, enquanto seu $\mathrm{PL}$ aumentou um pouco indo para $31,4 \%$. Em linhas gerais a companhia tem mais dívidas de longo prazo do que de curto prazo, e ainda possui PL positivo. Basicamente as dívidas que possui tanto de curto, quanto de longo prazo são decorrentes de empréstimos e financiamentos. Em relação ao Passivo, é possível perceber um aumento dos Empréstimos e Financiamentos de curtos e de longos prazos, uma vez que entre 2014 e 2015 , estes cresceram $81,9 \%$ e $36,4 \%$ respectivamente, sendo que ambos foram responsáveis pelo crescimento de $35 \%$ do PC e de $32,7 \%$ do PNC. No ano seguinte, constatou-se que os Empréstimos e Financiamentos de curto e de longos prazo diminuíram em 44,5\% e 18,8\% respectivamente. Esses fatos influenciaram na diminuição de 10,6\% do Passivo Total da empresa em relação a 2015.

Com relação a análise vertical da DRE, foi possível identificar um prejuízo de $\mathrm{R} \$$ 21.924.000,00 no final de 2014. Este resultado é consequência da alta participação dos Custo dos Bens e/ou Serviços Vendidos, que consumiu sozinho de 76,1\% da Receita de Vendas, e das Despesas Operacionais, que absorveram 30,3\% do faturamento da empresa. Assim, verificou-se que essas duas contas fizeram com que o Lucro Operacional fosse negativo, o que impossibilitou de a empresa arcar com as demais despesas, e consequentemente de obter prejuízo líquido neste ano. Em 2015 a situação de prejuízo líquido da empresa piorou, uma vez que o mesmo foi para $R \$$ 35.171.000,00. Apesar do Custo dos Bens e/ou Serviços vendidos terem apresentado uma pequena redução em termos de participação da receita total de vendas e ter ido para $69,4 \%$, as Despesas Operacionais da companhia, em 2015 cresceram e foram para 34,7\%. Deste modo, o Lucro Operacional da empresa se mostrou negativo, porém com um prejuízo menor do que o ano de 2014. Mas como as Despesas Financeiras também apresentaram aumento significativo em relação ao ano anterior (2,7\% para $10,2 \%$ de participação da receita total), tal situação levou a um aumento do prejuízo líquido da empresa.

Ao final de 2016 a Petrobrás começou a apresentar sinais de melhora, já que neste ano, ela conseguiu um Lucro Operacional positivo de $\mathrm{R} \$ 16.482 .000,00$, representando 5,8\% da Receita de Vendas do ano analisado. Esse resultado se mostrou diferente dos anos anteriores devido uma expressiva redução das Despesas Operacionais que foi para 26\%. Mas, como a empresa manteve a mesma participação de suas Despesas Financeiras em 2016, tal situação contribuiu para a empresa obter prejuízo líquido no referido ano de $\mathrm{R} \$ 13.045 .000,00$.

Quanto à análise horizontal da DRE, entre 2014 e 2015 a companhia apresentou queda de $13,1 \%$ no Custo de Bens e/ou Serviços Vendidos e aumento de 9,2\% das Despesas Operacionais. Assim, a redução do Custo de Bens e/ou Serviços Vendidos fez com que o prejuízo caísse em $39,8 \%$ de um ano para o outro. Entretanto, as Despesas financeiras cresceram 255,6\% em 2015, sendo estas as responsáveis pelo resultado final negativo da empresa, que cresceu 60,4\%. Em 2016 a Petrobrás apresentou sinais de recuperação, pois seu Custo dos Bens e/ou Serviços Vendidos apresentaram novamente redução de $13,7 \%$ comparado com 2015 . Do mesmo modo, as Despesas Operacionais regrediram 34,2\% entre 2015 e 2016. Tudo isso contribuiu para que o Lucro Operacional da empresa apresentasse um aumento de 225\%. As Despesas Financeiras também tiveram queda de 6,3\% em 2016 e por fim, o prejuízo da empresa apresentou uma redução de 62,9\% de 2015 para 2016. No entanto, mesmo apresentando melhora da administração dos custos e despesas, o resultado da companhia em 2016 se manteve com prejuízo, assim como os demonstrados nos anos anteriores.

\section{ANÁLISE DE ÍNDICES ECONÔMICO-FINANCEIROS}

É importante considerar também a análise dos demonstrativos contábeis por meio dos índices financeiros, que segundo Gitman (1997) trata-se de uma ferramenta necessária para 
avaliar o desempenho financeiro e a situação econômica de uma empresa no decorrer de determinado período. Nessa pesquisa, os índices financeiros utilizados foram classificados em quatro grandes grupos: liquidez, atividade, endividamento e lucratividade.

Observando os índices de liquidez da Petrobrás, percebe-se que em 2014 a companhia tinha um índice de liquidez geral de 2,24, que em 2015 teve um pequeno decréscimo e foi para 2,19 e em 2016 o mesmo subiu atingindo o valor de 2,62. Assim com relação à liquidez geral, a empresa se mostrou capaz de atender as suas obrigações de curtos e de longos prazos, já que para cada $R \$ 1,00$ dos seus compromissos totais, a petrolífera teve $R \$ 1,62$ em 2016 de ativos para atendê-los. A liquidez corrente da empresa, que segundo Gitman (1997) é a capacidade da empresa para atender suas obrigações somente de curto prazo, em 2014 era de 1,63 e em 2015 teve uma pequena queda para 1,51. Mas em 2016 a empresa demonstrou uma melhora da sua liquidez corrente, encerrando período com um índice de 1,8 . No que diz respeito ao índice de liquidez seca, não houve mudanças significativas, pois em 2014 a empresa apresentava um índice de 1,09 , no ano seguinte apresentou um inexpressivo aumento para 1,10 , com uma pequena redução para 1,07 em 2016. Do mesmo modo, os índices de liquidez imediata da empresa não apresentaram alteração no período analisado e se mantiveram no patamar médio de 0,87 .

Quanto aos índices de atividades, foi possível perceber que prazo médio de rotação dos estoques (PMRE) da companhia está aumentando, pois em 2014 era de 42,69 dias, no ano de 2015 aumentou para 48,02 dias e em 2016 foi para 52,97 dias, ou seja, o PMRE aumentou 10 dias de 2014 para 2016, significando que o estoque da empresa está demorando mais tempo para ser consumido. Por conta do aumento de 10 dias no PMRE, o capital investido nas contas circulantes está levando mais tempo para retornar para o caixa da Petrobrás, que apresentou um aumento do ciclo operacional na mesma proporção nos anos analisados.

Em relação ao prazo médio de recebimento de duplicatas (PMRD), a petrolífera manteve praticamente o mesmo patamar, pois de 2014 a 2016 levou em média 23 dias para receber suas contas junto aos seus clientes. Quanto ao prazo médio de pagamento (PMP), em 2014 a Petrobrás demorava 51,91 dias para pagar os seus fornecedores, já em 2015 e 2016 demorou em média 58,44 dias. Assim, percebeu-se que a companhia levou mais tempo para quitar as suas dívidas junto aos seus fornecedores.

Levando em consideração que para uma empresa existir, são necessários financiamentos, analisou-se por meio dos índices de endividamento o nível de recursos de terceiros que se encontravam investidos no AT da Petrobrás. Em 2014 a petrolífera demonstrou um índice de endividamento geral de $60,84 \%$. Isso significa dizer que mais da metade do seu AT foi financiado com recursos de terceiros. Em 2015 observou-se um aumento desse índice para 71,35\% e em 2016 uma pequena redução para 68,60\%. Em complemento a esta análise, destaca-se o índice de Participação de Capital de Terceiros que demonstrou que a sociedade empresária possuía um elevado grau de alavancagem financeira de $155,33 \%$. Assim, no ano de 2014 , para cada $\mathrm{R} \$ 100,00$ de capital próprio investido, a Petrobrás apresentou $\mathrm{R} \$ 55,33$ de capital de terceiros. Entretanto, a estratégia de financiamento dessa sociedade chamou atenção, pois percebeu-se que esta dobrou o uso dos recursos de terceiros em relação ao seu patrimônio líquido no ano de 2015 e 2016, os quais aumentaram para $248,98 \%$ e $218,48 \%$ respectivamente.

Em relação aos índices de lucratividade, verificou-se que a companhia em 2014 teve uma Margem Bruta correspondente à 23,85\%, que passou para 30,65\% em 2015 e 31,84\% no ano de 2016. No entanto, apesar da Margem Bruta ter se mostrado crescente de 2014 a 2016, não proporcionou resultados positivos à petrolífera, que apresentou prejuízos em todos os anos analisados. Por fim, os prejuízos líquidos das operações, não trouxeram retornos financeiros para os ativos e para os sócios da Petrobrás. 


\section{CONSIDERAÇÕES FINAIS}

Resumidamente a Petrobrás utilizou amplamente recursos de terceiros de curto e de longo prazo nos três anos analisados, sendo que o seu PNC representou, em média, 55\%, e o seu PC, em média, $11 \%$ do seu Passivo Total. Em relação ao seu Ativo Total, em média $71 \%$ está aplicado em ativos imobilizados (ANC), que são considerados bons investimentos, uma vez que estes servem para as atividades operacionais das empresas, e $18 \%$ em ativos de curto prazo (AC). No decorrer do período estudado, a Petrobrás conseguiu reduzir seus custos de bens e/ou serviços vendidos e suas despesas operacionais, entretanto nesse mesmo período, suas despesas financeiras aumentaram drasticamente, consequência da alta utilização de capital de terceiros na estrutura de capital da empresa, que também foi confirmada pelos índices elevados de endividamento. Em consequência do alto endividamento, a empresa obteve prejuízo líquido nos três anos analisados. Deste modo, os resultados dos índices de rentabilidade foram comprometidos em concordância com os fatos citados. Em contrapartida, os índices de atividade da empresa apresentaram resultados positivos, sendo que o seu ciclo financeiro foi de apenas 15 na média, ou seja, a Petrobrás precisou autofinanciar suas atividades somente neste período curto de dias. Do mesmo modo, os índices de liquidez da empresa denotaram uma situação favorável à esta, ou seja, a empresa apresentou boa capacidade de pagamentos de curto prazo no período 2014-2016.

\section{REFERÊNCIAS BIBLIOGRÁFICAS}

ASSAF NETO, A. Estrutura e Análise de Balanços: Um Enfoque Econômico-Financeiro. 10 ed. São Paulo: Atlas, 2012.

BLATT, A. Análise de Balanços: Estruturação e Avaliação as Demonstrações Financeiras e Contábeis. São Paulo: Makron Books, 2001.

CERVO, A. L.; BERVIAM, P. A.; DA SILVA, R. Metodologia científica. 6 ed. São Paulo: Pearson Prentice Hall, 2007.

DANTAS, I. Contabilidade: introdução e intermediária. Rio de Janeiro: Freitas Bastos, 2015.

GIL, C. A. Como Elaborar Projetos de Pesquisa. 5 ed. São Paulo: Atlas, 2010.

GITMAN, L. J. Princípios De Administração Financeira. 7 ed. São Paulo: Harbra, 1997.

GUERRA, E. L. de S. Manual de Pesquisa Qualitativa. 2014. Disponível em: <http://disciplinas.nucleoead.com.br/pdf/anima_tcc/gerais/manuais/manual_quali.pdf >. Acesso em: 29 mar. 2017.

SILVEIRA, D.T.; CÓRDOVA, F. P. A pesquisa científica. In: GERHARDT, T. E.; SILVEIRA, D. T. (org.). Métodos de Pesquisa. Porto Alegre: Editora UFRGS, 2009. p. 31 - 42. 2017. 